ISSN 1981-416X

Licenciado sob uma Licença Creative Commons

\title{
Cultura digital na escola: um estudo a partir dos relatórios de Políticas Públicas no Brasil
}

\author{
Digital culture in school: a study based \\ on the Public Policy reports in Brazil
}

\section{Fernando José de Almeida ${ }^{[a]}$, Siderly do Carmo Dahle de Almeida ${ }^{[b]}$, Alvaro Martins Fernandes Junior ${ }^{[b]^{*}}$}

\author{
[a] Pontifícia Universidade Católica de São Paulo (PUC-SP), São Paulo, SP, Brasil \\ [b] Centro Universitário Internacional Uninter, Curitiba, PR, Brasil
}

\section{Resumo}

A educação configura-se como protagonista nos programas de países que delinearam como meta valorizar a qualidade de vida de seus cidadãos. Esta conjuntura aponta para a iminência em se conseguir retorno célere, legítimo e efetivo para a interrupção de ciclos de pobreza e o estabelecimento de objetivos que promovam a liberdade, a harmonia e o progresso. Considerando-se o contexto das Políticas Públicas quanto ao uso de tecnologias nas escolas, o objetivo desta pesquisa foi perceber se a proposta pedagógica de inclusão digital já é uma realidade nacional. Para isso, realizou-se um estudo tendo por base 4 documentos oficiais. Dentre as questões levantadas, percebe-se que não há muita diferença quanto ao uso de TIC entre escolas públicas e privadas, além disso, o celular é apontado

*FJA: Doutor em Filosofia da Educação, e-mail: fernandoalmeida43@gmail.com SCDA: Doutora em Educação, e-mail: siderly.c@gmail.com AMFJ: Mestre em Gestão do Conhecimento, e-mail: alvarojunior777@gmail.com 
como meio pelo qual mais se acessa a internet e que quando uma instituição enfatiza a cultura digital, assume a centralidade na formação de alunos mais autônomos.

Palavras-chave: Cultura digital nas escolas. Inclusão digital nas escolas. TIC e políticas públicas.

\section{Abstract}

Education is a protagonist in the programs of countries that outlined the goal to value the life quality of its citizens. This situation points to the imminence of achieving a speedy, legitimate and effective return to the interruption of cycles of poverty and the establishment of objectives that promote freedom, harmony, and progress. Considering the context of public policies regarding the use of technologies in schools, the objective of this paper was to understand if the pedagogical proposal of digital inclusion is already a national reality. For this, a study was carried out based on 4 official documents. Among the issues raised is that there is not much difference regarding the use of ICTs between public and private schools, that the cell phone is pointed out as the medium through which the Internet is accessed the most and that when an institution emphasizes the digital culture, it assumes the centrality in the formation of more autonomous students.

Keywords: Digital Culture in Schools. Digital Inclusion in Schools. ICT and Public Policies.

\section{Introdução}

Confia-se aos cuidados da educação a esperança de que esta venha contribuir para a evolução e a prosperidade da humanidade, considerando-se os preceitos de sustentabilidade e democracia. Deste modo, é possível reduzir a fome, a segregação social, a privação de oportunidades, a insegurança em todos os âmbitos, problemas comuns que afligem e aniquilam populações ao redor do mundo. 
A partir da década de 90 a educação tomou lugar na agenda da comunidade científica, que se voltou para a repercussão de que a educação formal pode representar grande contribuição quanto ao desenvolvimento das nações. Organizaram-se pactos, estabeleceram-se compromissos e definiram-se objetivos que pudessem garantir a oportunidade de acesso à escola, considerando-se seus diferentes níveis, desde a Educação Infantil até a Educação Superior, assim como formação profissional, técnica, permanente, sem se esquecer do vínculo que se faz entre educação e mundo do trabalho e da prática social.

A Lei de Diretrizes e Bases da Educação Nacional — LDBEN 9394/96 é um claro exemplo desta posição assumida por países em processo de desenvolvimento, ao tecer todo o documento embasando sua inspiração "nos princípios de liberdade e nos ideais de solidariedade humana” (BRASIL, 1996).

Neste mesmo período histórico, que se inicia na década de 90, observa-se uma efervescência advinda das tecnologias digitais de informação e de comunicação que passam a interferir nos mais diversos setores da sociedade: do modo como uma notícia chega ao seu destino ao modo com as instituições comerciais vendem os seus produtos. Verificam-se mudanças significativas ainda no que diz respeito ao lazer, ao setor de serviços, a indústria e a educação, ponto central deste estudo, cujas instituições passam por modificações em suas estruturas.

Apenas vinte anos depois da promulgação da LDBEN no Brasil é que há uma alteração em que se considera as tecnologias: A lei 13.415 de fevereiro de 2017, acrescenta em seu artigo 35 o termo "e suas tecnologias" ao referir-se às áreas do conhecimento: linguagens, matemática e ciências da natureza (BRASIL, 2017), evidenciando a importância de se pensar nas áreas do conhecimento também sob o enfoque das tecnologias, ainda que de forma não muito definida e clara.

O objetivo desta pesquisa é perceber se a proposta pedagógica de inclusão digital nas escolas já é uma realidade nacional. Para isso, realizou-se um compilado de quatro textos dos últimos 3 anos que abordam tal assunto. São os seguintes documentos: 
- “TIC Educação 2016: pesquisa sobre o uso das tecnologias de informação e comunicação nas escolas brasileiras", produzido pelo Comitê Gestor da Internet no Brasil (CGI Br, 2017);

- "Marco Referencial Metodológico para a Medição do Acesso e Uso das Tecnologias de Informação e Comunicação (TIC) na Educação", produzido pelo Centro Regional de Estudos para o Desenvolvimento da Sociedade da Informação (CETIC, 2016);

- "Pesquisa brasileira de mídia 2015: hábitos de consumo de mídia pela população brasileira" desenvolvida pela Secretaria de Comunicação Social da Presidência da República (BRASIL, 2014);

- “TIC Educação e desenvolvimento social na América Latina e o Caribe" um documento redigido por Enrique Hinostroza, diretor do Instituto de Informática Educativa da Universidad de la Frontera do Chile (UNESCO, 2017).

A comparação entre os dados demonstrados nestes quatro documentos pautou-se no aluno da educação básica enquanto unidade de análise, excluindo-se nesse contexto a educação infantil. As categorias investigadas referem-se ao perfil demográfico dessa população, ao perfil específico relacionado ao uso das TIC nas escolas e às atividades escolares, considerando-se as tecnologias usadas e o modo como contribuem com o processo de ensino e de aprendizagem.

$\mathrm{O}$ estudo estruturou-se em quatro partes assim distribuídas: esta introdução esclarecendo contexto, objeto, objetivo e categorias de análise; um tópico remontando as últimas três décadas da educação e o uso de tecnologias, fundamentando-se em autores como Levy (1999), Castells (1999, 2004), Galimberti (2006); um tópico explicitando metodologia, apresentação e análise de dados e, em uma última parte, as considerações finais da pesquisa. 


\section{Breve histórico da integração da Informática no Brasil}

Na década de 70 do século passado os computadores já estavam nos centros de processamento de dados das universidades brasileiras, e tinham como finalidade, prioritariamente, o seu uso administrativo, mas também era timidamente utilizado para investigações específicas.

As iniciativas referentes à aplicação de tecnologias digitais de informação e de comunicação na educação básica despontaram em meados da década de 1980. Nestas, levava-se em consideração, de modo especial, o empenho em se instituírem Políticas Públicas que concebessem o preparo de profissionais para atuação em novos cenários que se delineavam no mundo.

Embora ainda rudimentar, o Brasil possuía uma Secretaria de Informática, a SEI (Secretaria Especial de Informática), órgão vinculado ao Conselho Nacional de Segurança e responsável por regulamentar, coordenar, supervisionar e fomentar o desenvolvimento do setor. Foi em 1983 que esta secretaria instituiu a Comissão Especial no 11/83 Informática na Educação, que tinha como objetivo propor a orientação básica, os padrões de especificação técnica de equipamento, a localização dos recursos e o monitoramento da implementação dos centros-piloto (MORAES, 1993). E, em 1984, estavam implantados os primeiros centros na Universidade Estadual de Campinas, Universidade Federal de Minas Gerais, Universidade Federal de Pernambuco, Universidade Federal do Rio de Janeiro e Universidade Federal do Rio Grande do Sul.

O estabelecimento de políticas de inclusão digital torna-se urgente e a educação é apontada como primordial neste cenário. Tais políticas passam, a partir do fim do século passado, a oferecer incentivo para o desenvolvimento de pesquisas na área, assim como programas de qualificação profissional e formação continuada de docentes e, ainda, inclusão de dispositivos tecnológicos nas escolas, considerando-se a implantação de infraestrutura e conexão à rede internet. Inicia-se um período de distintos desafios a serem superados dentro e fora da escola, entre estes, a desigualdade social e a democratização do acesso à informação e à cultura. 


\section{A integração das tecnologias no processo de aprendizagem}

Para Castells, a partir da década de 70 iniciaram-se três movimentos históricos autossuficientes que confluíram para a "gênese de um novo mundo" (1999, p. 412). A princípio houve uma crise do capitalismo e um declínio do Estado e sua consecutiva reestruturação, nomeada pelo autor como "capitalismo informacional": O princípio baseia-se na "produção pelo lucro e para a apropriação privada dos lucros com base nos direitos de propriedade" (p. 413). Contudo, tal reestruturação visa o desenvolvimento e a expansão tecnológica, o acúmulo de informação e, consequentemente, a complexidade nos processos de produção, desenvolvimento e disseminação do conhecimento em lugar da potencialização da produção de bens consumíveis.

O segundo movimento primordial para o novo perfil da sociedade contemporânea, associa-se à culminância da organização de distintos movimentos sociais e culturais, que instituem o cenário para rupturas nos alicerces da sociedade. Castells (1999) refere-se a temas que envolvem as questões de gênero, os cuidados com a vida no planeta, a defesa dos direitos humanos, entre outros. Esses movimentos surgem como resposta em oposição à autoridade, às desigualdades sociais, aos valores apregoados pelo tradicionalismo religioso e buscava exaltar a liberdade de cada indivíduo. As tecnologias, segundo o autor, determinaram as bases intelectuais para um mundo novo a que ele denomina "sociedade em rede" (CASTELLS, 1999).

Concomitantemente a esses dois movimentos, intercorreu um terceiro, que é o de transformação da sociedade e que se encontra estreitamente relacionado à revolução causada pelas tecnologias digitais da informação, que funciona recompondo os alicerces materiais da sociedade, por intermédio do informacionalismo: atributo da "forma específica de organização social em que a geração, o processamento e a transmissão da informação tornam-se fontes fundamentais de produtividade e poder [...]" (CASTELLS, 2006, p. 65). 
Cunham-se aqui as expressões "sociedade informacional" e "economia informacional" empregados por Castells para diferenciar as transformações sociais, culturais e econômicas contemporâneas e ainda elevar as atribuições da informação e do conhecimento neste contexto.

Galimberti (2006) evidencia que nesta "sociedade tecnológica" existe uma transição nas condições que refletem a relação do homem com a natureza e com ele mesmo. A mudança paradigmática do que era a Sociedade Industrial para a Sociedade do Conhecimento (ou Tecnológica) assinala mudanças de concepção produtiva de quantidade para qualidade. A técnica surge então como condição sine-qua-non para decodificar o mundo conferindo-lhe conceitos que o seu próprio uso técnico lhe permite.

Pierre Lévy aponta que a tecnologia traduz a habilidade que a humanidade tem para dar impulso ao seu domínio das tecnologias, por meio de suas instituições sociais. A obra desse autor, de um modo geral, é importante para a compreensão do uso que o homem faz da tecnologia, tendo em vista sua formação voltada para a ciência da informação e da comunicação. Especificamente em seu livro "Cibercutura”, Lévy define três princípios essenciais que orientaram o crescimento inicial do ciberespaço: "a interconexão, a criação de comunidades virtuais e a inteligência coletiva” (LÉVY, 1999, p. 127). Neste sentido, o conhecimento gerado e compartilhado no ciberespaço parte do princípio da reciprocidade, ou seja, o que é útil a uma pessoa pode ser útil para muitas outras pessoas. Esse novo ciclo de conhecimento tecnológico permitiu aos usuários interagirem com os instrumentos aprendendo, se apropriando de seus mecanismos e redefinindo sua forma de utilizá-lo.

Em busca de propiciar a articulação entre distintas áreas de saber, especialmente nas duas primeiras décadas do século XXI, as instituições de ensino procuraram utilizar o computador como uma ferramenta de aprendizagem no desenvolvimento de projetos. Nesta última perspectiva, o computador é usado pelo aluno para configurar a solução de um problema ou implantar um projeto, criando seus próprios modelos mentais. 


\section{Almeida (2007) analisa que}

Se você pensa na qualidade da educação, o computador pode dar uma contribuição realmente grande. Mas não é ele sozinho. Ele tem que compor um projeto político-pedagógico da escola. O computador só pode ajudar uma escola que tem um projeto pedagógico bom. Se a escola não tiver projeto, ou tiver um projeto equivocado, mal elaborado, fragmentado, o computador piora esse projeto, esse projeto fica pior ainda. Na verdade, o computador é um otimizador do bom ou do péssimo. Com ele, o projeto da escola pode ficar muito pior, se o projeto for ruim (ALMEIDA, 2007, p. 120).

Assim, seguiram-se programas de governo advindos das esferas Federal, Estadual e Municipal. Ainda, surgiu o interesse das instituições privadas de ensino de inserir em seus currículos tecnologias digitais de informação e comunicação, por um lado atraindo alunos em todos os níveis de ensino e, por outro, preocupando-se com a formação do professor para este novo contexto.

De acordo com Almeida e Valente (2016)

Devem ser oferecidas oportunidades aos professores para a apropriação pedagógica das mídias e TIC, de modo que eles possam integrá-las aos processos de ensino, aprendizagem, desenvolvimento do currículo, avaliação e pesquisa sobre a própria prática, utilizando-as para atender às necessidades dos alunos. Com tais competências, os professores se tornam capazes de analisar por quê, para quê, com o quê, como e quando integrar esse conhecimento à prática pedagógica (ALMEIDA; VALENTE, 2016, p. 37).

Almeida e Valente salientam ainda que é substancial proporcionar que todos os envolvidos no processo educativo - gestores, professores, alunos, equipe pedagógica, membros do conselho da escola e da comunidade - se mobilizem e elaborem um plano que articule "infraestrutura, recursos físicos, financeiros e de infraestrutura, tempo e espaço da escola" (2016, p. 37), propiciando e encadeando o diálogo entre todos e oportunizando o acesso e o uso de tais tecnologias no ambiente escolar. 
Os professores que atuam com educação básica compreendem que aliar tecnologia ao currículo permite diversificadas formas de interação: professor - aluno, aluno - professor, aluno - aluno; oferece informações variadas, superficiais ou aprofundadas, sobre todos os assuntos; torna a aula mais agradável e com maior interesse por parte dos alunos; expande a aprendizagem para além da sala de aula e da escola; favorece a socialização dos saberes; auxilia na inclusão digital tanto de alunos como dos próprios professores.

Considerando que estas discussões figuram como objeto de estudo e de trabalho de muitos pesquisadores ao redor do mundo, especialmente nos últimos trinta anos, este estudo voltou-se a aferir o acesso da população às tecnologias digitais, de modo a atingir o objetivo proposto, que é investigar se, efetivamente, as tecnologias digitais de informação e comunicação são utilizadas na educação brasileira.

\section{Metodologia, apresentação e análise de dados}

Conforme anunciado na introdução deste artigo, este estudo respaldou-se em quatro documentos:

- o “TIC Educação 2016; o Marco Referencial Metodológico para a Medição do Acesso e Uso das Tecnologias de Informação e Comunicação (TIC) na Educação", a "Pesquisa brasileira de mídia 2015: hábitos de consumo de mídia pela população brasileira" desenvolvida pela Secretaria de Comunicação Social da Presidência da República (BRASIL, 2014) e o "TIC Educação e desenvolvimento social na América Latina e o Caribe" um documento redigido por Enrique Hinostroza, diretor do Instituto de Informática Educativa da Universidad de la Frontera do Chile para a UNESCO (UNESCO, 2017). 
A unidade de análise deste estudo foi o aluno que frequenta a educação básica. As categorias eleitas para maior aprofundamento são o perfil demográfico dessa população, o perfil específico relacionado ao uso das TIC nas escolas e as atividades escolares, considerando-se as tecnologias usadas e como os professores fazem uso das mesmas.

Considerando-se a pesquisa TIC Educação 2016, foi utilizada a Parte 2, que apresenta o relatório metodológico e a análise dos resultados do TIC Educação 2016. Com relação ao Marco Referencial, produzido pelo CETIC, foram analisados os textos que se referem aos dilemas entre as práticas instrutivas e a cultura digital na integração entre currículo e TIC. O foco do terceiro documento, a Pesquisa Brasileira de Mídia 2015, foi o capítulo 3 - A Internet - que, logo em sua introdução, alerta que a internet foi apontada por $42 \%$ dos brasileiros $\left(1^{\circ}+2^{\circ}+3^{\circ}\right.$ lugares $)$ como o meio de comunicação mais utilizado, ficando atrás da televisão (93\%) e, por uma pequena diferença, do rádio (46\%) (BRASIL, 2014). No último documento que compõe o estudo fez-se uma leitura de todo o texto por se tratar de um documento breve, porém que merece atenção por apresentar dados da América Latina e Caribe no decorrer do ano de 2016.

\section{TIC educação 2015: pesquisa sobre o uso das tecnologias de informação e comunicação nas escolas brasileiras}

A pesquisa TIC Educação teve por objetivo reconhecer o acesso, a utilização e a apropriação das TIC nas escolas públicas e privadas do país, tanto no que concerne à prática pedagógica quanto à gestão escolar, investigando as escolas, os diretores, os coordenadores pedagógicos, os professores e os alunos. Como anteriormente explicitado, especificamente neste estudo, a unidade de análise escolhida foi o aluno e, dessa forma, o olhar dos pesquisadores seguiu nesta direção.

Importante ressaltar que no instrumento de coleta de dados do TIC Educação, no que diz respeito aos alunos "foram excluídas as questões sobre: uso de rede $W i F i$ da escola mesmo que restrita, habilidades 
gerais, local de realização de atividades escolares com uso de Internet. Foi incluída questão sobre utilização do telefone celular em atividades escolares com orientação do professor" (CGI Br, 2017). A unidade de análise, portanto, recai sobre 1.087 Instituições de Ensino que responderam ao questionário de alunos, somando 11.069 alunos respondentes.

Do ponto de vista dos alunos sobre o uso de tecnologias digitais que os seus professores fazem, demonstra-se que estão bem satisfeitos, não sendo apontadas diferenças entre Instituições públicas e privadas, mas sim entre os níveis de ensino e idade dos alunos, conforme aponta o Gráfico 1.

Gráfico 1 - Alunos, por percepção sobre possíveis impactos das tic (2016)

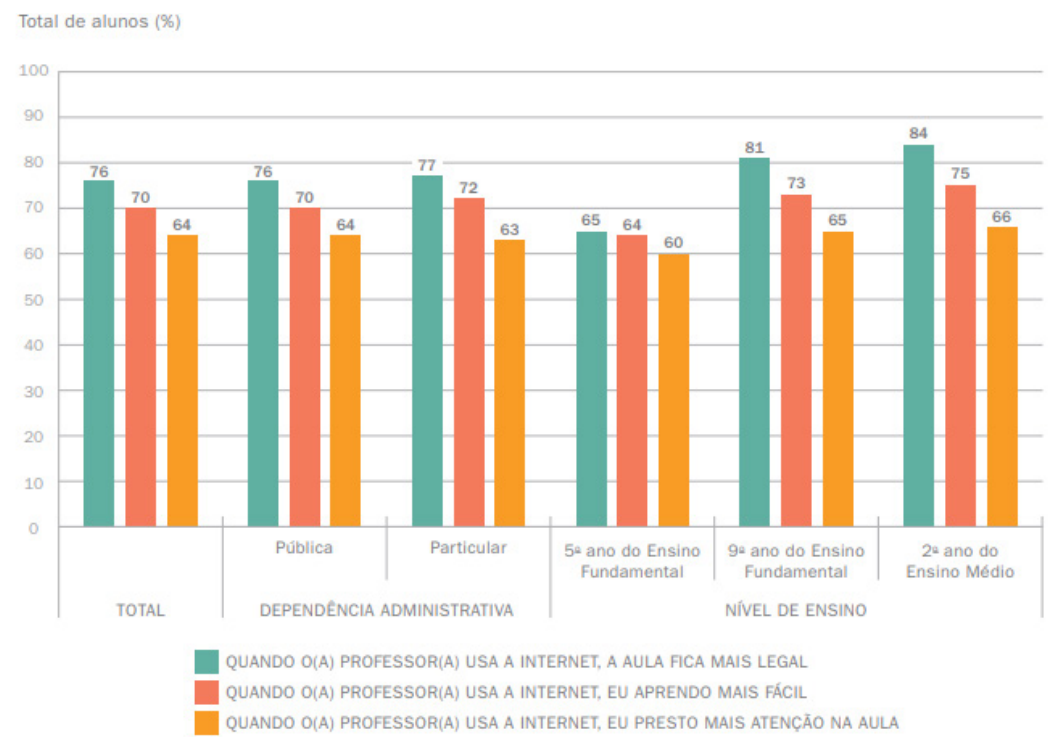

Fonte: CGI Br, 2017.

Estes dados evidenciam que há uma grande semelhança entre as respostas dadas por alunos de escolas públicas e privadas sobre a motivação e a aprendizagem que a internet proporciona, independentemente do nível em que os alunos estudam. Contudo, do $5^{\circ}$ ano ao fim do Ensino 
Médio observa-se uma curva crescente na preferência pelo uso de tecnologias, ou seja, quanto maior a idade, maior a conexão.

Outro dado importante refere-se à ubiquidade que, segundo Almeida e Valente (2016), tem a ver com o uso de mídias e tecnologias digitais, independentemente do tempo e do espaço em que o indivíduo esteja. Refere-se aos dispositivos móveis e aos serviços que ficam nas nuvens e permitem acesso instantâneo e interação entre as pessoas que se encontram temporal e espacialmente distantes. Considerando-se o contexto educacional, o telefone celular foi apontado por professores e alunos como o meio pelo qual mais acessam a internet, seja para verificar as redes sociais, quanto para realização de tarefas escolares. Segundo dados da pesquisa,

O telefone celular foi o principal dispositivo para acesso à Internet para 77\% dos alunos usuários da rede, sendo que em 2015 essa proporção era de $73 \%$. Ao mesmo tempo, o acesso à Internet prioritariamente por outros equipamentos, como computadores de mesa (9\%) e notebooks (6\%) apresenta tendência de redução (CGI Br, 2017).

Quanto ao acesso à internet pelo celular, outro dado interessante é que deste total de alunos, $21 \%$ estão em escolas públicas e $5 \%$ em escolas privadas. Isso ocorre porque os alunos de escolas particulares utilizam outros meios de acesso e, com a popularização do celular, o mesmo tornou-se o principal dispositivo entre os diversos segmentos da população, inclusive os de menor renda.

Importante verificar que, apesar de haver uma grande parcela da população com possibilidade de acesso à internet, ainda há um percentual de alunos desconectados: "Na região Norte 29\%, no Nordeste (18\%), Sul (14\%), Centro-Oeste (12\%) e Sudeste (11\%)” (CGI Br, 2017, p. 110). Nesse sentido há, ainda, muito o que se fazer na busca por diminuir a exclusão digital.

Segundo dados da pesquisa, em 2016 ainda havia um número imenso de escolas que proibiam o uso do celular em sala de aula: $5 \%$ de alunos das escolas públicas e $9 \%$ de escolas particulares disseram ser permitido utilizar o celular em sala de aula (CGI Br, 2017). A esta informação, 
soma-se ainda o número limitado de escolas com redes de Wifi que permitem acesso a seus estudantes, $61 \%$ das escolas não liberam as senhas de acesso aos seus alunos.

\section{Marco referencial metodológico para a medição do acesso e uso das tecnologias de informação e comunicação (TIC) na educação}

Este documento, elaborado em 2016, teve por objetivo produzir um marco referencial que determinasse dimensões e indicadores oportunos para apresentar respostas referentes ao contexto regional da América Latina, mais especificamente do Brasil, dispondo da "produção sistemática de estatísticas comparáveis internacionalmente e ao mesmo tempo relevantes para as políticas públicas específicas de cada país" (CETIC, 2016).

Ressalta-se no texto que a Agenda 2030 para o Desenvolvimento Sustentável das Organizações das Nações Unidas (ONU) apresenta atitudes e critérios transformadores para a prosperidade dos cidadãos e do planeta como um todo, de modo a vencer "o desafio de promover, de forma equilibrada, as três dimensões do desenvolvimento sustentável em nível global: crescimento econômico, inclusão social e a sustentabilidade ambiental" (CETIC, 2016). O objetivo 4 desta agenda exalta a educação de qualidade de maneira a propiciar educação inclusiva e equitativa e, ainda, oportunizar aprendizagem ao longo da vida para todos. Tais desafios, de acordo com o relatório, podem ser enfrentados com a adoção das tecnologias digitais como fonte de acesso ao conhecimento e como ferramenta pedagógica.

O texto esclarece que frente às transformações inerentes às práticas sociais estreitamente influenciadas pela cultura digital, a educação se vê frente a dilemas que apresentam a falsa noção de oposição entre duas distintas visões de currículo, sendo preciso ressaltar as convergências entre "as práticas sociais da cultura digital, as políticas públicas e as intenções educativas" (CETIC, 2016). Desta forma, a instituição de ensino que se envolve com a cultura digital, estabelecendo os necessários diálogos com a mesma, assume a centralidade na formação do aluno autônomo, 
direcionando-o para que saiba argumentar e defender suas ideias, trabalhar em grupo com respeito às distintas ideias de seus colegas, atuar de forma crítica, ativa, criativa e questionadora.

A ideia aqui é a de que os alunos aprendem com os professores, assim como, os professores aprendem com os alunos. Jesus e Tasson explicitam que

Nessa relação dialógica (professor-aluno) há produção de conhecimentos profissionais, a partir da observação de que nem todas as práticas e ou intervenções planejadas são eficazes, pois, às vezes, as crianças redirecionam a forma de olhar, para algo que não havia sido previsto. Nesse sentido, as crianças atuam na zona de desenvolvimento proximal do professor, fazendo-o pensar em outras formas de se trabalhar, visando acolher os questionamentos das crianças para fazê-las se sentirem parte do processo (JESUS; TASSON, 2017, p. 237)

O documento enfatiza que com o uso das tecnologias digitais de informação e comunicação, novas práticas disseminam-se no espaço escolar:

- Uso de jogos digitais (games) e o desenvolvimento de novos jogos pelos estudantes;

- Participação em redes sociais e comunidades criadas na Internet em torno de um tema de interesse;

- Uso, criação e compartilhamento de Recursos Educacionais Abertos (REA) disponíveis na web;

- Produção de vídeos, animações e narrativas digitais sobre experiências dos estudantes;

- Uso e a criação de aplicativos sobre temas específicos do currículo escolar, tais como simulações, experimentos virtuais;

- Participação dos estudantes em laboratórios virtuais de ciências;

- Participação coletiva na criação de cidades virtuais e na discussão de suas problemáticas;

- Criação de glossários digitais sobre temas específicos (CETIC, 2016). 
Entre os fatores que favorecem a cultura digital da escola, a premissa é o acesso ininterrupto à Internet, de forma pública e gratuita, a todos os pertencentes ao processo educacional. O texto explicita que é essencial permitir a "disponibilidade contínua, de qualidade e de capacidade adequada da infraestrutura tecnológica da escola, o que deve considerar políticas efetivas de suporte e manutenção da infraestrutura TIC" (CETIC, 2016).

\section{Pesquisa brasileira de mídia 2015: hábitos de consumo de mídia pela população brasileira}

Esta pesquisa é o maior levantamento acerca dos hábitos de informação dos cidadãos brasileiros e refere-se ao que aconteceu no decorrer do ano de 2014. Importa particularmente neste estudo verificar o uso da internet que apontava que, no período, $48 \%$ da população fazia uso da rede. Quanto ao tempo de conexão, observava-se que os usuários "ficam conectados, em média, 4h59 por dia durante a semana e 4h24 nos finais de semana". No ano anterior, a média era de 3h39 e 3h43.

O relatório aponta que $51 \%$ das pessoas ainda não utilizavam a internet em 2014 e que entre os que utilizavam, 67\% buscavam informações e notícias de modo geral, "de diversão e entretenimento (67\%), de uma forma de passar o tempo livre (38\%) e de estudo e aprendizagem (24\%)" (BRASIL, 2014, p. 49).

Com relação ao nível de ensino, verificou-se que $72 \%$ das pessoas com Ensino Superior acessam a internet por aproximadamente 5 h41. As pessoas que possuem apenas os anos iniciais do Ensino Fundamental utilizam muito menos, apenas $5 \%$ por 3 h22. $65 \%$ dos jovens de 16 a 25 anos se conectam por 5 h51 e $4 \%$ daqueles que tem 65 anos ou mais a utilizam por 2h53 (BRASIL, 2014).

Neste ano começa-se a haver equilíbrio entre o acesso por meio de celular e por meio de computadores de mesa - 66\% e 71\%, respectivamente. 
Entre as redes sociais e os programas de trocas de mensagens instantâneas mais usadas $\left(1^{\circ}+2^{\circ}+3^{\circ}\right.$ lugares), estão o Facebook (83\%), o Whatsapp (58\%), o Youtube (17\%), o Instagram (12\%) e o Google+ (8\%). O Twitter, popular entre as elites políticas e formadores de opinião, foi mencionado apenas por $5 \%$ dos entrevistados. Em relação aos principais suportes de acesso à internet $\left(1^{\circ}+2^{\circ}\right.$ lugares $)$, os resultados mostram que a maioria dos entrevistados $(71 \%)$ o fazem via computador, seguido pelo celular (66\%). Há ainda uma pequena parcela (7\%) dos pesquisados que utiliza tablets para navegar pelo mundo digital (BRASIL, 2014).

A pesquisa brasileira de mídia não apresenta com clareza os dados sobre o público que frequenta a escola, foco deste estudo, porém, apresenta dados importantes com relação ao tempo médio de conexão dos brasileiros, além das preferências quanto a redes sociais e quanto ao uso do computador, que ganhava por uma pequena diferença do uso do celular quando se fala em conexão com internet.

\section{TIC educação e desenvolvimento social na américa latina e o caribe}

Este documento, redigido pelo Dr. Enrique Hinostroza, diretor do Instituto de Informática Educativa da Universidad de la Frontera do Chile para a Unesco procura "levantar debates multidisciplinares, propor análises baseadas em evidência e formular propostas de políticas públicas para consolidar uma estratégia de desenvolvimento sustentável necessária na America Latina e o Caribe, no âmbito da Agenda 2030" (UNESCO, 2017, p. 3).

Explicita-se que, para a democratização do acesso à cultura digital, faz-se necessário vencer dois desafios: o acesso livre e gratuito a computadores conectados à internet e que tal conectividade seja de boa qualidade. Outro ponto levantado no documento é que existe uma grande disponibilidade de recursos educacionais abertos, porém, não há um padrão de qualidade que contribua para a seleção, uso e disseminação destes recursos. 
Importa também lembrar que as competências digitais devem ser integradas ao currículo escolar de modo a contribuir para que as futuras gerações aproveitem este potencial. Para isso, é imprescindível que os professores incluam o uso da tecnologia em sua prática pedagógica, visando a construção do conhecimento:

incorporar ou reforçar o uso das TIC na educação, e promover o desenvolvimento de programas que incluam a formação de professores, novos modelos pedagógicos, geração, adaptação e intercâmbio de recursos educacionais abertos, a gestão das instituições de educação e avaliações pedagógicas (UNESCO, 2017, p. 6).

O Brasil se encontrava em 2016 com igual acesso a computadores e à Internet, na faixa dos 50\%, o que representa ainda muito pouco e, portanto, denota a necessidade de programas voltados tanto para a infraestrutura e possibilidade de aquisição de hardwares e acesso à rede, quanto para a formação das pessoas para o uso desses equipamentos.

Este documento também evidencia a necessidade de

garantir aos estudantes o acesso contínuo (na escola e em casa) a computadores, principalmente ao grupo de estudantes de nível socioeconômico inferior; oferecer conexão à Internet a escolas mais distantes dos centros urbanos; e melhorar a qualidade do acesso à Internet, ou seja, garantir a conexão de banda larga com a velocidade necessária para que se possa tirar proveito dos recursos e serviços disponíveis. Além disso, em termos gerais, aconselha-se incentivar iniciativas para oferecer conexão à Internet de qualidade aos estudantes e professores fora da escola (UNESCO, 2017, p. 14).

De todo o modo, o documento alerta para o fato de que a escola não tem conseguido realizar a integração das tecnologias ao currículo, seja pela falta de infraestrutura, seja pela falta de formação pedagógica para tal uso. Além disso, alerta que a verdadeira integração acontece fora da sala de aula, evidenciando a necessidade de que os docentes se 
prepararem com maior rigor para o desenvolvimento das competências digitais, tão necessárias para a atuação na escola contemporânea.

O texto conclui que, concatenado aos benefícios latentes das tecnologias digitais, existem muitos desafios que precisam ser enfrentados e solucionados, como por exemplo, a falta de acesso a essas tecnologias, assim como o despreparo da população para fazer uso da mesma.

\section{Considerações finais}

Esta pesquisa teve por objetivo perceber se a proposta de inclusão digital já é uma realidade nas escolas. Para isso, realizou-se um compilado de quatro textos oficiais dos últimos 4 anos que abordam tal assunto. $\mathrm{O}$ confronto entre as informações contidas nestes quatro documentos norteou-se no aluno da Educação básica enquanto unidade de análise. As categorias investigadas orientaram-se no perfil demográfico dessa população, no perfil específico relacionado ao uso das TIC nas escolas e nas atividades escolares, considerando-se as tecnologias usadas e o modo como contribuem com o processo de ensino e de aprendizagem.

$\mathrm{Na}$ análise de cada um dos documentos é possível afirmar que o acesso, a utilização e a apropriação das TIC nas escolas públicas e privadas do país, no que concerne à prática pedagógica, se faz de modo muito semelhante, demonstrando que os docentes estão sim preocupados com tal inserção no contexto escolar, sendo menos utilizado nos anos iniciais do Ensino Fundamental, exacerbando-se o uso nos anos finais e no Ensino Médio.

Observou-se que os alunos, tanto de escolas públicas quanto de escolas privadas, sentem-se mais motivados e dizem aprender melhor quando fazem uso da internet e, quanto mais velhos, maior também o tempo de conexão.

A pesquisa do CGI Br (2017) demonstrou que o telefone celular é o principal dispositivo de acesso à internet, tanto na escola, quanto em casa, por professores e por alunos. O documento enfatiza ainda que há 
um grande percentual de alunos desconectados, especialmente na região Norte e no Nordeste.

A pesquisa do CETIC (2016) avalia que a educação se encontra em um dilema quando o assunto é tecnologia e currículo. É preciso perceber as convergências entre ambas e incentivar o seu desenvolvimento. Assim, não basta levar a tecnologia para a sala de aula, é preciso concretizar o currículo por meio desta. Desse modo, torna-se possível formar o aluno autônomo, crítico, reflexivo, que sabe ouvir e se posicionar frente ao conhecimento, seja ele apresentado pelo professor ou por seus colegas. Para poder integrar efetivamente a tecnologia ao currículo, o documento apresenta uma série de práticas que favorecem a introdução de uma cultura digital nas escolas.

Quanto aos hábitos dos brasileiros com relação ao uso de tecnologias de modo geral, em 2014, $48 \%$ da população estava conectada e ficava em média 5 horas por dia na internet. Considerando o nível de ensino da população, verificou-se que $72 \%$ das pessoas com Ensino Superior acessam a internet por aproximadamente $5 \mathrm{~h} 41$. As pessoas que possuem apenas os anos iniciais do Ensino Fundamental utilizam muito menos, apenas $5 \%$ por $3 \mathrm{~h} 22.65 \%$ dos jovens com 16 a 25 anos se conectam por 5h51. Mais uma vez se verifica que, quanto mais velho, mais tempo conectado à rede.

A pesquisa contribui no sentido de levar a compreensão de que para a democratização efetiva do acesso à cultura digital é preciso que haja acesso gratuito aos equipamentos, assim como conectividade gratuita e de boa qualidade. Outra questão importante é que se busque avançar mais na qualidade dos recursos educacionais abertos oferecidos à população.

Vencidos os desafios, as competências digitais precisam ser integradas ao currículo escolar, qualificando as futuras gerações para melhor viver/conviver na sociedade do conhecimento. Cabe ainda enfatizar que, a escola, enquanto espaço que não pode prescindir de estar na vanguarda no que se refere ao uso das tecnologias na educação, precisa investir na qualificação de seu corpo docente. 


\section{Referências}

ALMEIDA, F. J. Moçambique está ficando perto: depoimento [2007]. Entrevistadora: Nilce da Silva. Revista Eletrônica Acolhendo a Alfabetização nos Países de Língua Portuguesa, São Paulo, USP, 2007. (Depoimento: Entrevista concedida ao Grupo Acolhendo Alunos em Situação de Exclusão Social, da Faculdade de Educação da Universidade de São Paulo e Pós-Graduação em Educação de Jovens e Adultos, da Faculdade de Educação da Universidade Eduardo Mondlane). Disponível em: <https://www.revistas.usp.br/reaa/ article/viewFile/11451/13219>. Acesso em: 17 jun. 2018.

ALMEIDA, M.; ELIZABETH, B.; VALENTE, J. A. Políticas de tecnologia na Educação Brasileira: histórico, lições aprendidas e recomendações. In: Centro de Inovação para a educação brasileira, 2016. Disponível em: <http://www.cieb.net.br/ wp-content/uploads/2016/12/CIEB-Estudos-4-Politicas-de-Tecnologia-naEducacao-Brasileira.pdf $>$. Acesso em: 10 out. 2017.

BRASIL. Lei no 9.394, de 20 de dezembro de 1996. Estabelece as diretrizes e bases da educação nacional. Brasília: Ministério da Educação, 1996.

BRASIL. Lei 13.415, de 16 de fevereiro de 2017. Altera as Leis nos 9.394, de 20 de dezembro de 1996, que estabelece as diretrizes e bases da educação nacional, e 11.494, de 20 de junho 2007, que regulamenta o Fundo de Manutenção e Desenvolvimento da Educação Básica e de Valorização dos Profissionais da Educação, a Consolidação das Leis do Trabalho - CLT, aprovada pelo DecretoLei no 5.452, de 1o de maio de 1943, e o Decreto-Lei no 236, de 28 de fevereiro de 1967; revoga a Lei no11.161, de 5 de agosto de 2005; e institui a Política de Fomento à Implementação de Escolas de Ensino Médio em Tempo Integral. Brasília, 2017.

BRASIL. Presidência da República. Secretaria de Comunicação Social. Pesquisa brasileira de mídia 2015: hábitos de consumo de mídia pela população brasileira. Brasília: Secom, 2014.

CASTELLS, M. Cibercultura. São Paulo: Ed. 34, 1999. 
CASTELLS, M. A sociedade em rede. 8. ed. rev. e ampl. São Paulo: Paz e Terra, 2006. CETIC. Marco Referencial Metodológico para a Medição do Acesso e Uso das Tecnologias de Informação e Comunicação (TIC) na Educação. In: Centro Regional de Estudos para o desenvolvimento da Sociedade da Informação - Brasil. São Paulo: Unesco, 2016.

CGI Br - COMITÊ GESTOR DA INTERNET NO BRASIL. Pesquisa sobre o uso das tecnologias de informação e comunicação nas escolas brasileiras: TIC educação 2016 [livro eletrônico] = Survey on the use of information and communication technologies in brazilian schools: ICT in education 2016. São Paulo: Comitê Gestor da Internet no Brasil, 2017.

GALIMBERTI, U. Psiche e techne, o homem na idade da técnica. São Paulo: Paulus, 2006. JESUS, D. C. C. de; TASSON, E. C. M. Escritas de mim: narrativas e a autoformação docente. EccoS - Rev. Cient., São Paulo, n. 44, p. 225-240, set./dez. 2017.

LÉVY, P. Cibercultura. São Paulo: Ed. 34, 1999.

MORAES, M. C. Informática Educativa no Brasil: um pouco de História. Em Aberto, Brasília, ano 12, n. 57, jan./mar. 1993. Disponível em: <http://emaberto.inep.gov. br/index.php/emaberto/article/view/1877/1848>. Acesso em: 17 jun. 2018.

UNESCO. TIC Educação e desenvolvimento social na América Latina e o Caribe. Montevideu: Unesco, 2017.

Recebido: 22/08/2018

Received: 08/22/2018

Aprovado: 10/09/2018

Approved: 09/10/2018 